\title{
COMPARISON OF THE BODY BUILD AND PHYSICAL ABILITIES OF THE STUDENTS OF SPORTS CLASSES AND ORDINARY CLASSES
}

\author{
Raini Stamm ${ }^{1}$, Meelis Stamm ${ }^{2}$, Margot PähN ${ }^{1}$, \\ Aleksander JAIRUS ${ }^{1}$ \\ ${ }^{1}$ Institute of Health Sciences and Sport, Tallinn University, Tallinn, Estonia \\ ${ }^{2}$ Faculty of Educational Sciences, Tallinn University, Tallinn, Estonia
}

\begin{abstract}
The aim of the current study was to analyse and compare the peculiarities of physical abilities and body build of the students of the primary school classes (Year 1-4) of ordinary classes and sports classes at Tallinn Lilleküla Secondary School.

The sample consisted of 170 primary school students - 93 boys and 77 girls. It involved 56 boys and 29 girls in sports classes and 37 boys and 48 girls in ordinary classes. The body height and weight of all the students were measured and their BMI was calculated. All the students also performed four physical abilities tests, which were standing long jump test, forward bending test, $4 \times 10 \mathrm{~m}$ shuttle run test ja 3 minute endurance run test. The reliability and validity of these tests have been checked earlier.

Arithmetic means and standard deviations were calculated. To find the differences between the groups and assess the results, Student's paired t-test was used; the lowest level of significance was set at $\mathrm{p}<0.05$.

The study revealed that, comparing the test results of boys' and girls' physical abilities, differences appear with an increase in age. In most cases, boys of Year 4 outdo girls statistically significantly. Girls are better than boys only in flexibility.

Physical abilities tests showed that in nine cases statistically significant differences in physical abilities appeared between the students of the ordinary class and the sports class. In eight cases, the mean result in physical abilities was better in the sports classes than in the ordinary classes.

In their stature and physical abilities the students of primary school classes of Tallinn Lilleküla Secondary School are similar to their peers Estonia.
\end{abstract}

Keyword: testing, physical fitness, children, anthropometry 


\section{INTRODUCTION}

A fashionable trend among present-day youth is not to be physically active and to play in the world of information technology rather. Not many children can be seen playing, moving, running, cycling, etc. in the open air after school. One of the reasons is that children play computer games or interact with their peers on the Internetchildren and their parents. As a rule, children who are engaged in sports in their free time already are in a good shape physically.

Several studies have shown that higher self-esteem is a positive and motivating factor in the context of physical activities and achievements $[1,8,9,11]$. Fox [2] has found that high self-esteem is associated with choices, stability and success in the area of behaviour related to efficiency and health.

Lilleküla Secondary School does not admit students to the sports class or the ordinary class based on their physical abilities or tests results them but according to children's and their parents'wishes. In the sports class they receive daily lessons of physical education after their regular school day. In recent years, parents have often enrolled children in the sports class because the child is slightly overweight, sedentary and likes to spend time eating crisps in front of the TV. Therefore, it was interesting to analyse and compare the peculiarities of physical abilities and body build of primary school students attending ordinary classes and sports classes at Tallinn Lilleküla Secondary School.

\section{MATERIAL AND METHODS}

The subjects of the current study where the students of Lilleküla Secondary School who, during the study, were students of Years 1-4. The sample consisted of 170 students -93 boys and 77 girls. It involved 56 boys and 29 girls in sports classes and 37 boys and 48 girls in ordinary classes.

The subjects participating in the study were tested with the consent of their parents and the school administration. All the tests were conducted at the school - at the lessons of physical education and sports. The participants were the students of Years 1-4 of Lilleküla Secondary School in the autumn of the academic year 2014/2015. The tests were performed by the students of classes A or sports classes and classes B or ordinary classes.

The study was conducted in the autumn of 2014 - in October and November - when children performed the tests. 


\section{Testing of physical abilities}

1) Standing long jump. The test measures explosive strength of leg muscles.

The subjects jump from half squat as far as they can, landing on both feet; it is recommendable to remain in the standing position. Three jumps are performed. The subjects have to push off with both feet and land have on both feet simultaneously.

The length of the jump is measured in centimetres from the take-off line (from the edge of the adhesive tape) to the nearest point where an impression is made in the pit by any part of the jumper's body. The best attempt of the three is counted. The score is measured in centimetres [3].

2) Flexibility test. The test measures forward bending.

The result is given in centimetres. The testee stands on a bench in socks, feet together, soles against the bench, with straight knees and performs a forward bend [3].

3) $4 \times 10 \mathrm{~m}$ shuttle run test. The test measures running speed, reaction speed and speed of changing the motion direction of the body.

The testee stands behind the start line with the whole body behind the line. After the signal, the testee runs as quickly as possible to the end of the stretch. Behind the line opposite the starts line there are two blocks that the testee brings, one by one, behind the start line. The block has to be placed on the ground; throwing is not allowed.

The result is the running time in seconds and tenths of seconds. The finishing time is clocked at the moment when the second block is placed on the ground [6].

4) Three minutes endurance run. The aim of the test is to measure aerobic capacity.

The result is the distance run during three minutes measured in metres [3].

\section{Anthropometric measuring}

The students' height $(\mathrm{cm})$ and weight $(\mathrm{kg})$ were measured using the methodology of Martin [7, 5]. From these results, each student's BMI was calculated $\left(\mathrm{kg} / \mathrm{m}^{2}\right)$. 


\section{Statistical data analysis}

When processing the data, arithmetic means $(\bar{X})$ and standard deviations $( \pm S D)$ were found. To find the differences between the groups and to assess the results, Student's paired t-test was used; the lowest level of significance was set at $\mathrm{p}<0.05$.

\section{RESULTS}

*Statistically significant differences between the physical abilities of girls and boys and between the students of ordinary classes and sports classes.

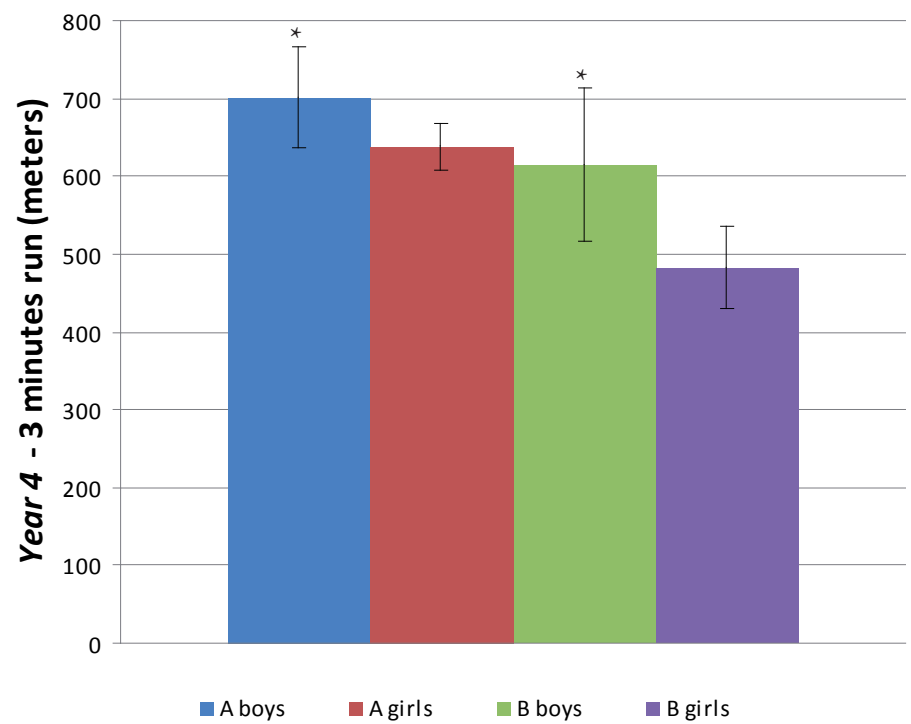

* Statistically significantly differences between the results of boys and girls of class A and class B $(p<0.05)$

Figure 1. Results of three minutes endurance run of boys and girls of Year 4 in the sports class (A) and the ordinary class (B).

While in Years 1, 2 and 3, boys' and girls' mean results of endurance run were relatively similar and no statistically significant differences could be found ( $>0.05$ ), then comparing the boys and girls of Year 4, we found statistically significant differences $(\mathrm{p}<0.05)$. Namely, the boys of the sports class in Year 4 had statistically significantly greater endurance than the girls of the sports class. In the ordinary class of Year 4, the boys also had statistically significantly more endurance than the girls (Figure 1). 


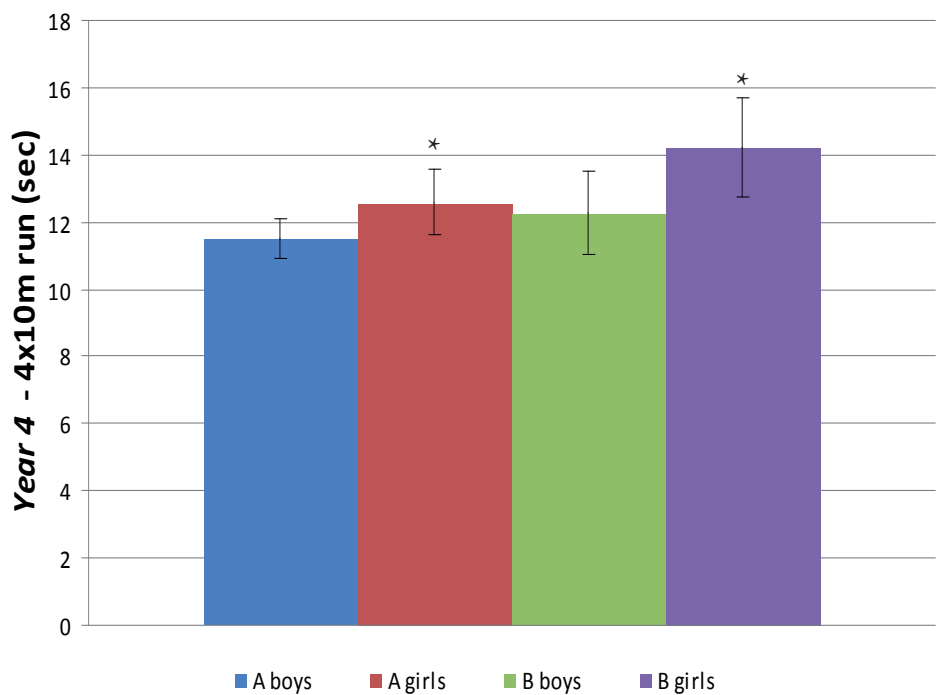

*Statistically significantly differences between the results of boys and girls of class A and the boys and girls of class B ( $p<0.05)$

Figure 2. Results of $4 \times 10 \mathrm{~m}$ shuttle run of boys and girls of Year 4 in the sports class (A) and the ordinary class (B).

Ordinary class girls of Year 4 were significantly weaker in standing long jump than the boys. There were no statistically significant differences between the students of the sports class ( $\mathrm{p}>0.05)$.

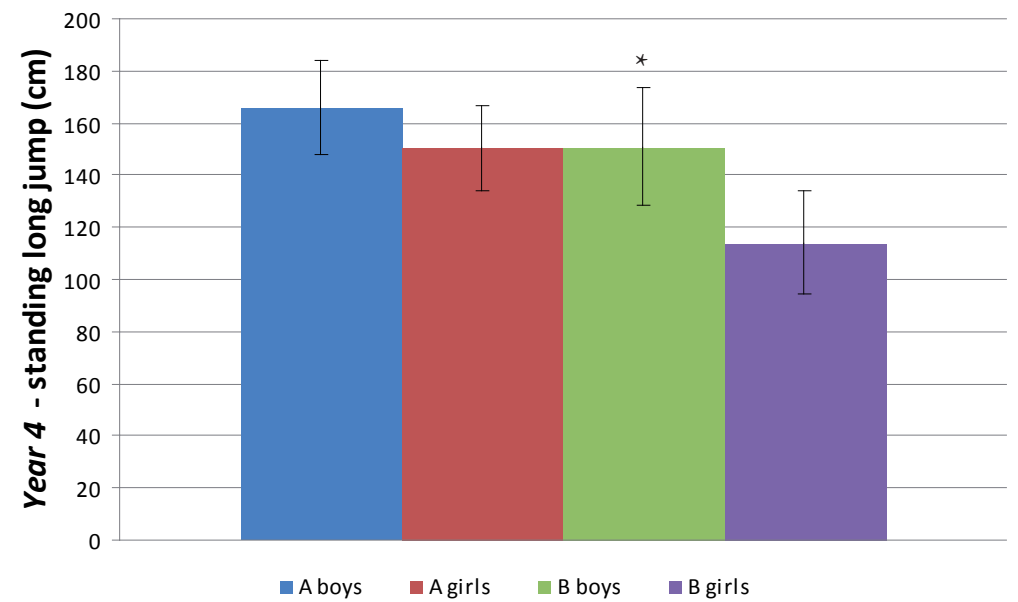

*Statistically significant differences in the results of class $B(p<0.05)$

Figure 3. Results of boys and girls of Year 4 in standing long jump in the sports class $(A)$ and the ordinary class (B). 
Forward bend in centimetres in boys of Year 4 in the sports class boys was significantly smaller than in girls (Figure 4 ). In the ordinary class there were no statistically significant differences between the boys and girls in the forward bending test $(\mathrm{p}>0.05)$.

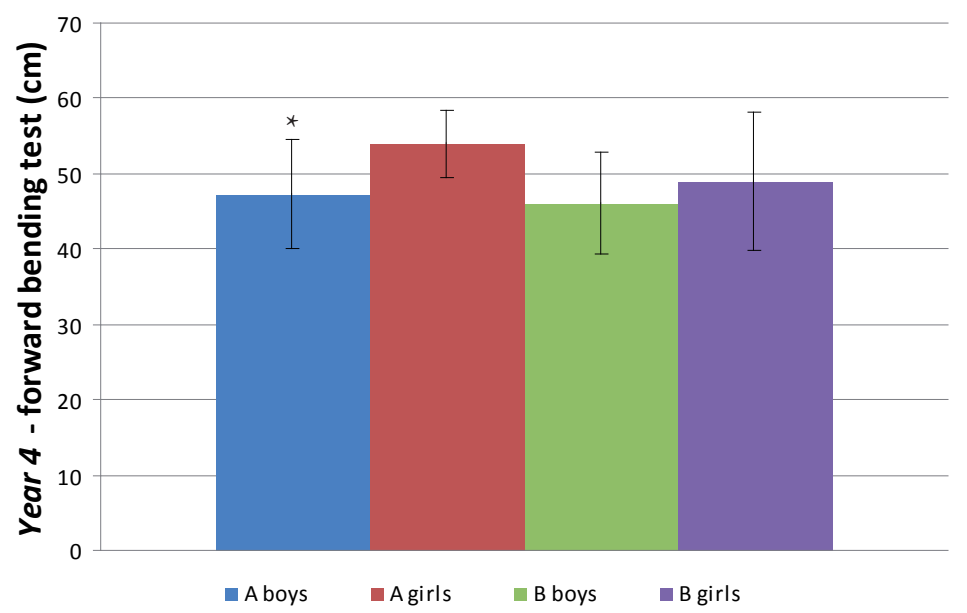

*Statistically significant differences in the results of class A $(p<0.05)$

Figure 4. Results of boys and girls of Year 4 in the forward bending test in the sports class (A) and the ordinary class (B).

Ordinary class girls of Year 3 are significantly more flexible than boys of the same age (Figure 5).

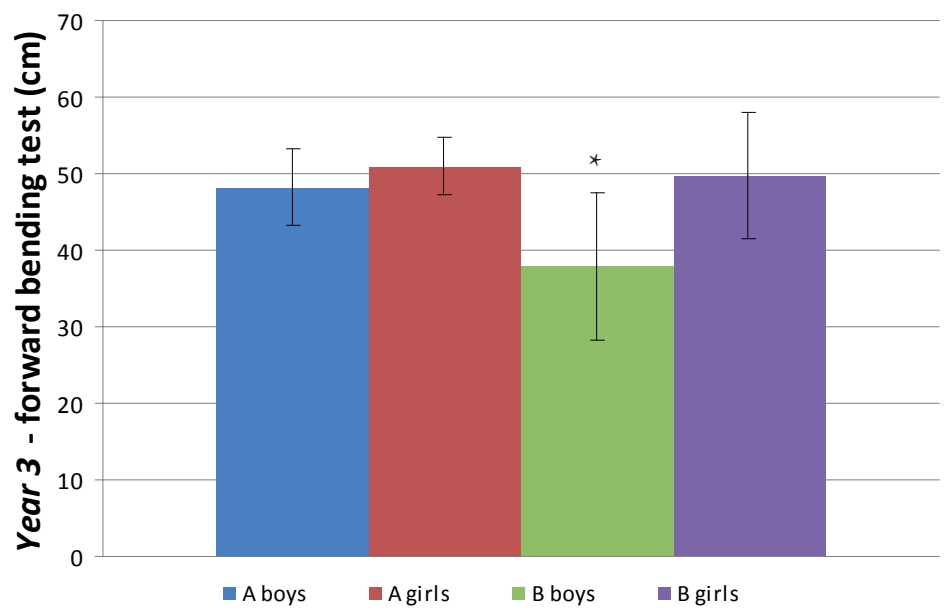

*Statistically significant differences in the results of class B $(p<0.05)$

Figure 5. Results of boys and girls of Year 3 in the forward bending test in the sports class (A) and the ordinary class (B). 


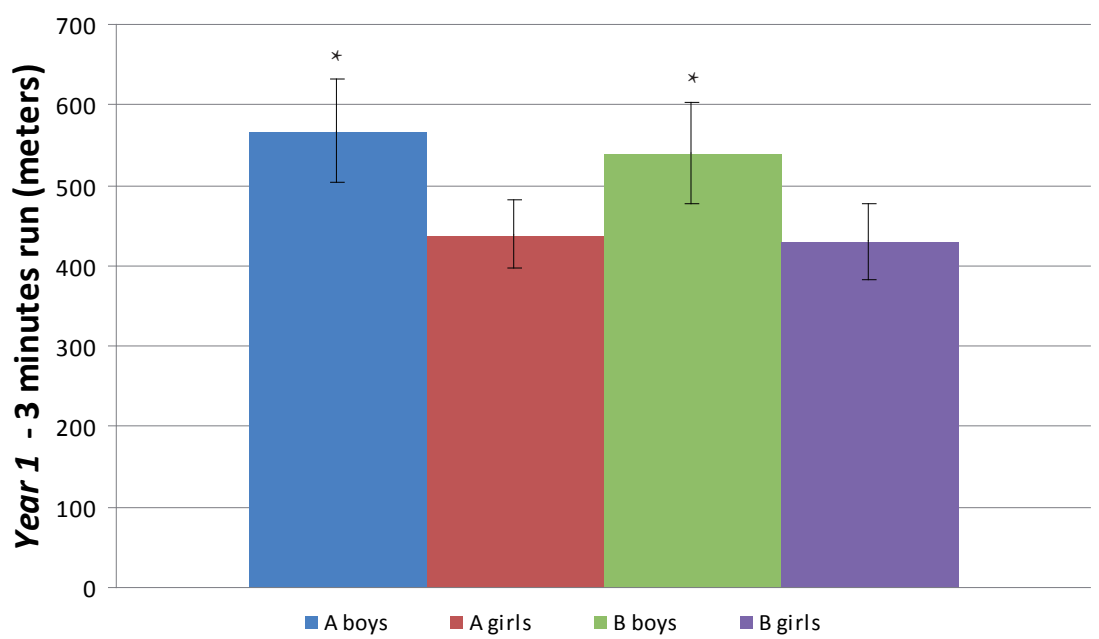

*Statistically significantly differences between the results of boys and girls of class A and the boys and girls of class B $(p<0.05)$

Figure 6. Results of three minutes endurance run of boys and girls of Year 1 in the sports class (A) and the ordinary class (B).

Next, we describe all the statistically significant differences that appeared while comparing the physical abilities tests of ordinary classes and sports classes of boys ja girls of different ages (Table 1). Girls of the ordinary classes of Years 2 and 4 are statistically significantly slower in shuttle run than the girls of the same age group in the sports classes. Year 4 girls of the ordinary class are statistically significantly weaker in standing long jump than the girls of the same age group in the sports class. Girls of Year 4 of the ordinary class run a significantly shorter distance in three minutes or have less endurance than the girls of the sports class. Girls of Year 1 in the ordinary class are statistically significantly weaker in standing long jump than the girls of the sports class. The results of boys of Year 3 and Year 1 of the ordinary classes in standing long jump were significantly weaker than those of the boys of the sports classes. Year 3 boys of the ordinary class bend forward for significantly fewer centimetres than the boys of the sports class. Year 4 boys and girls of the sports class have statistically significantly greater endurance than the boys and girls of the ordinary class (Table 1).

Physical abilities tests showed that statistically significant differences in physical abilities between the students of the ordinary class and the sports class appeared in nine cases. In all cases except one (shuttle run of Year 1 boys), the physical abilities of the students of the sports class were better than those of the students of the sports class of the ordinary classes. 
Table 1. Mean anthropometric characteristics and test results of boys and girls in the sports classes (A) and the ordinary classes (B)

\begin{tabular}{|c|c|c|c|c|c|c|c|}
\hline Girls & $\begin{array}{c}\text { Body mass } \\
(\mathbf{k g})\end{array}$ & $\begin{array}{l}\text { Height } \\
(\mathrm{cm})\end{array}$ & $\begin{array}{c}\text { BMI } \\
\left(\mathrm{kg} / \mathrm{m}^{2}\right)\end{array}$ & $\begin{array}{l}\text { Flexibility } \\
(\mathrm{cm})\end{array}$ & $\begin{array}{l}\text { Standing } \\
\text { long jump } \\
\text { (cm) }\end{array}$ & $\begin{array}{c}4 \times 10 m \text { run } \\
\text { (sec) }\end{array}$ & $\begin{array}{l}3 \text { min } \\
\text { run } \\
(\mathrm{m})\end{array}$ \\
\hline \multirow{2}{*}{$\begin{array}{c}1 A(n=7) \\
B(n=9)\end{array}$} & $28.9 \pm 6.5$ & $129.1 \pm 6.7$ & $17.2 \pm 2.4$ & $49.1 \pm 7.7$ & $124.7 \pm 18.4$ & $14.3 \pm 1.2$ & 439.3= \\
\hline & $28.7 \pm 3.4$ & $131.5 \pm 2.6$ & $16.5 \pm 1.9$ & $43.7 \pm 5.2$ & $109.4 \pm 8.0^{*}$ & $14.7 \pm 0.9$ & $430 \pm 46.1$ \\
\hline \multirow{2}{*}{$\begin{array}{l}2 A(n=5) \\
B(n=14)\end{array}$} & $26.7 \pm 4.0$ & $129.8 \pm 6.0$ & $15.7 \pm 1.4$ & $48.4 \pm 5.0$ & $117.8 \pm 21.0$ & $12.7 \pm 0.8$ & $606 \pm 86.6$ \\
\hline & $32.5 \pm 8.7$ & $136.6 \pm 3.5$ & $17.3 \pm 4.0$ & $47.6 \pm 4.7$ & $107.5 \pm 15.1$ & $14.3 \pm 1.4^{*}$ & $502.9 \pm 33.6$ \\
\hline \multirow{2}{*}{$\begin{array}{l}3 A(n=7) \\
B(n=15)\end{array}$} & $34.8 \pm 3.7$ & $138.4 \pm 3.2$ & $18.1 \pm 1.7$ & $51.0 \pm 3.7$ & $134.4 \pm 30.6$ & $13.1 \pm 1.3$ & $579.3 \pm 89.9$ \\
\hline & $34.3 \pm 7.7$ & $139.2 \pm 7.0$ & $17.5 \pm 2.8$ & $49.7 \pm 8.3$ & $131.1 \pm 22.6$ & $12.9 \pm 0.9$ & $540.9 \pm 118.0$ \\
\hline \multirow{2}{*}{$\begin{array}{c}4 A(n=10) \\
B(n=10)\end{array}$} & $34.9 \pm 5.3$ & $143.9 \pm 4.8$ & $16.8 \pm 1.8$ & $54.0 \pm 4.4$ & $150.4 \pm 16.4$ & $12.6 \pm 1.0$ & $638.0 \pm 29$ \\
\hline & $35.3 \pm 10.8$ & $143.2 \pm 7.3$ & $16.9 \pm 3.4$ & $49.0 \pm 9.2$ & $114.2 \pm 19.1^{*}$ & $14.2 \pm 1.4^{*}$ & $483.0 \pm 65.2^{*}$ \\
\hline Boys & $\begin{array}{l}\text { Body mass } \\
(\mathbf{k g})\end{array}$ & $\begin{array}{l}\text { Height } \\
(\mathrm{cm})\end{array}$ & $\begin{array}{c}\text { BMI } \\
\left(\mathrm{kg} / \mathrm{m}^{2}\right)\end{array}$ & $\begin{array}{l}\text { Flexibility } \\
(\mathrm{cm})\end{array}$ & $\begin{array}{l}\text { Standing } \\
\text { long jump } \\
\text { (cm) }\end{array}$ & $\begin{array}{l}4 \times 10 \mathrm{~m} \\
\text { run } \\
(\mathrm{s})\end{array}$ & $\begin{array}{c}3 \text { min } \\
\text { run } \\
(\mathrm{m})\end{array}$ \\
\hline \multirow{2}{*}{$\begin{array}{c}1 A(n=18) \\
B(n=12)\end{array}$} & $27.2 \pm 2.4$ & $130.9 \pm 4.6$ & $15.9 \pm 1.0$ & $47.6 \pm 5.7$ & $134.6 \pm 15.6$ & $13.7 \pm 1.2$ & $566.9 \pm 64.1$ \\
\hline & $29.4 \pm 3.6$ & $132.4 \pm 3.9$ & $16.7 \pm 1.3$ & $45.3 \pm 5.7$ & $116.4 \pm 18.2^{*}$ & $13.7 \pm 1.4$ & $540.8 \pm 63.3$ \\
\hline \multirow{2}{*}{$\begin{array}{c}2 A(n=14) \\
B(n=6)\end{array}$} & $32.1 \pm 6.9$ & $135.6 \pm 6.8$ & $17.3 \pm 2.5$ & $47.3 \pm 5.1$ & $131.1 \pm 13.6$ & $12.9 \pm 1.0$ & $591.1 \pm 60.8$ \\
\hline & $31.6 \pm 4.4$ & $138.5 \pm 4.1$ & $16.4 \pm 1.8$ & $47.2 \pm 3.5$ & $126.7 \pm 27.4$ & $13.5 \pm 1.5$ & $541.7 \pm 90.9$ \\
\hline \multirow{2}{*}{$\begin{array}{c}3 A(n=13) \\
B(n=8)\end{array}$} & $33.0 \pm 4.7$ & $141.2 \pm 3.9$ & $16.5 \pm 2.0$ & $48.2 \pm 5.0$ & $149.0 \pm 21.4$ & $12.2 \pm 1.2$ & $620.4 \pm 78.4$ \\
\hline & $36.8 \pm 13.1$ & $139.4 \pm 6.6$ & $18.6 \pm 5.3$ & $37.9 \pm 9.7^{*}$ & $132.5 \pm 12.0^{*}$ & $12.9 \pm 1.1$ & $544.3 \pm 85.4$ \\
\hline \multirow{2}{*}{$\begin{array}{c}4 A(n=11) \\
B(n=11)\end{array}$} & $35.6 \pm 6.0$ & $145.2 \pm 6.3$ & $16.6 \pm 2.2$ & $47.3 \pm 7.1$ & $166.0 \pm 18.1$ & $11.5 \pm 0.6$ & $701.4 \pm 64.3$ \\
\hline & $36.3 \pm 8.0$ & $143.5 \pm 5.6$ & $17.5 \pm 2.9$ & $46.2 \pm 6.8$ & $151.0 \pm 22.5$ & $12.3 \pm 1.2$ & $614.5 \pm 98.0 *$ \\
\hline
\end{tabular}

*Statistically significant difference with the sports class $(p<0.05)$

\section{Analysis of mean body build data comparing the boys and girls of sports classes and ordinary classes}

Table 1 shows the mean anthropometric variables and tests results of boys and girls in sports classes and ordinary classes. As the Table revearls, there were no significant differences in the body height of the students of the ordinary classes and sports classes $(p>0.05)$. Neither were there any significant differences between the body weight of the students of sports classes and ordinary classes $(p>0.05)$. There were no statistically significant differences in BMI between the students of sports and ordinary classes ( $p>0.05)$. 


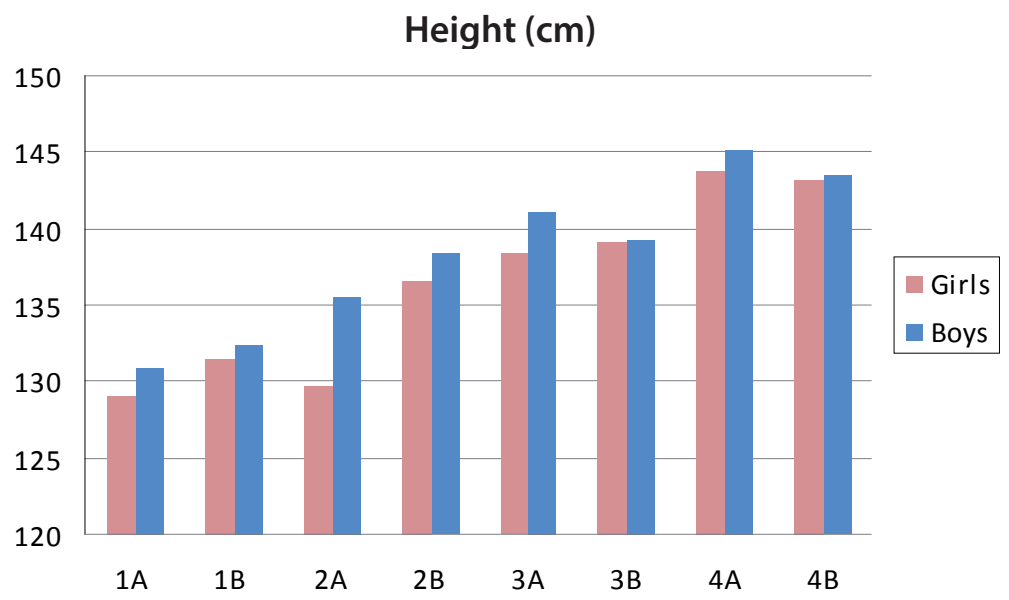

Figure 7. Body height of boys and of Years 1-4 in the sports classes (A) and the ordinary classes (B).

The tallest were the Year 4 boys of the sports class $(145.2 \mathrm{~cm})$ and after them the Year 4 girls the sports class $(143.9 \mathrm{~cm})$. The shortest were the Year 1 girls of the sports class $(129.1 \mathrm{~cm})$ and the Year 1 boys of the sports class $(130.9 \mathrm{~cm})$ (Figure 7).

\section{Body weight $(\mathrm{kg})$}

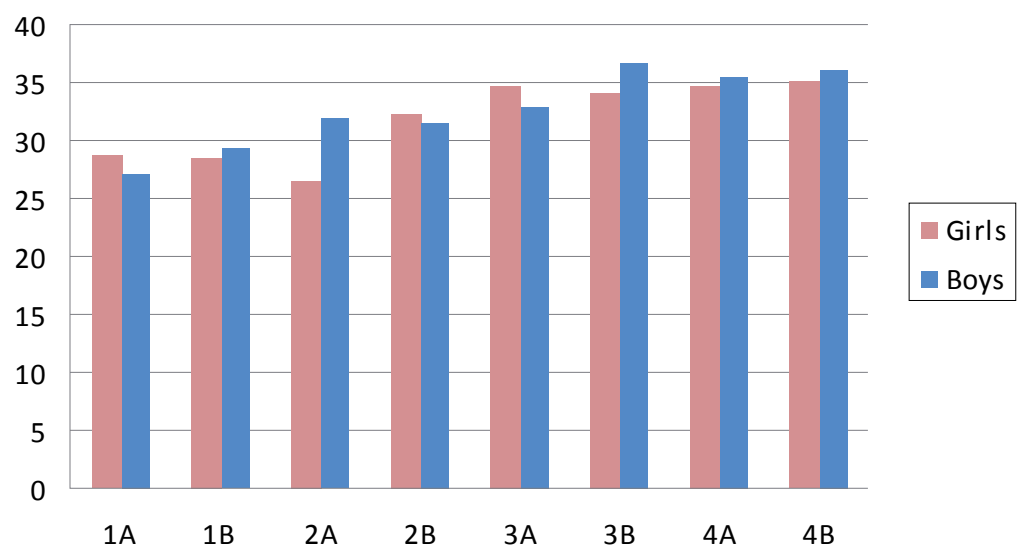

Figure 8. Body weight of boys and of Years $1-4$ in the sports classes $(A)$ and the ordinary classes (B).

Comparison of the mean body weight of boys ja girls revealed that in five cases the body weight of the students of sports classes was lower than that of the students or ordinary classes (Figure 8 ). In boys, the mean body height was 
greater in the sports classes (Figure 7). It is also noticeable that in all age groups boys had greater body height than girls. In Years 3 and 4, the boys of the sports classes had greater body height than the boys of the ordinary classes, but their body weight was lower than in the boys of the ordinary classes (Table 1).

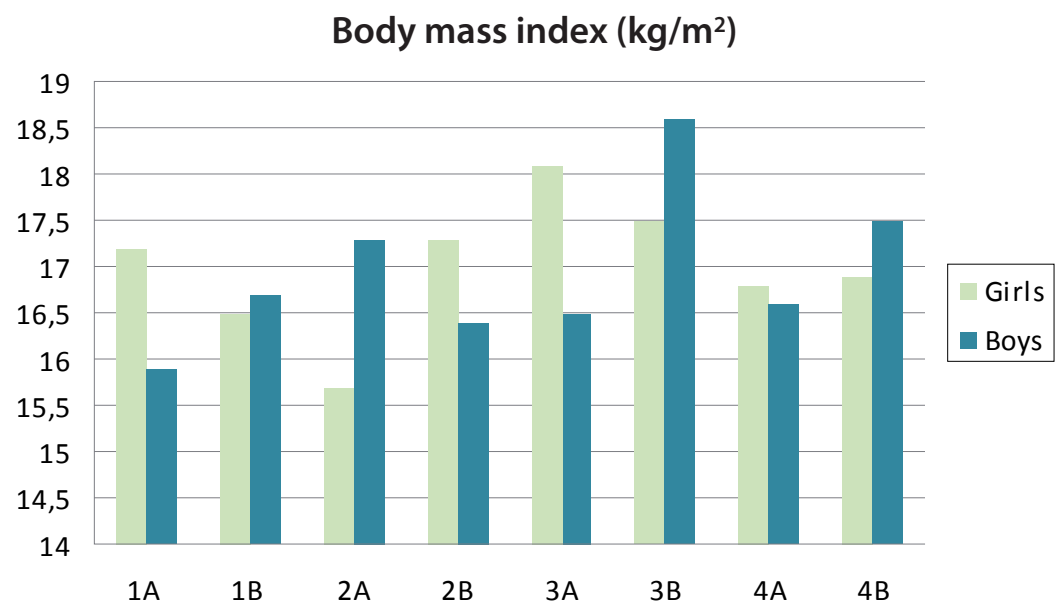

Figure 9. Mean BMI of boys and of Years 1-4 in the sports classes (A) and the ordinary classes (B).

Figure 9 shows changes in BMI from Year 1 to Year 4 in both boys and girls.

It is noticeable that in Year $4 \mathrm{BMI}$ of both boys and girls is greater in the ordinary class (Table 1). However, the difference was not statistically significant.

\section{DISCUSSION}

The aim of the current study was to find if and to what extent students of primary school age in the sports classes of Tallinn Lilleküla Secondary School differ from their peers in their physical abilities. To determine their physical abilites, tests were conducted $(4 \times 10 \mathrm{~m}$ shuttle run, standing long jump, forward bend standing on a bench and three minutes endurance run).

At this age, children grow so quickly that their physical abilities do not change quite significantly. There may be many physically talented students whose height and weight have increased so much by the next academic year that their physical abilities do not keep up with their growth.

The body heights and weights of the students of Lilleküla Secondary School are similar to Estonian norms [4], and no great differences occur. There is some difference in the body weight of Year 2 girls of the sports class, which is 
$26.7 \mathrm{~kg}$ (Table 1), but according to Estonian norms, it is $30.2 \mathrm{~kg}$. Some difference can also be noticed in the girls of Year 4, where the mean weight of the students of Lilleküla Secondary School is $34.9 \mathrm{~kg}$ (Table 1), but according to Estonian norms the weight of students of the same age is $38.2 \mathrm{~kg}$. No differences appeared when children's height was compared between sexes. According to studies conducted in Estonia, [4], the mean height of 7-year-old girls was $128.4 \mathrm{~cm}$ and that of boys $129.7 \mathrm{~cm}$. Our results for girls of the same age were $131.5 \mathrm{~cm}$ and for boys $132.4 \mathrm{~cm}$.

In youth sports, one has to consider that, at the age of 11-15 years, abrupt increase in height and weight occurs [10].

When comparing the results of physical abilities tests between boys and girls, differences appear with increase in age. In most cases, boys of Year 4 outdo girls statistically significantly. Girls are better than boys only in flexibility.

Physical abilities tests showed that statistically significant differences in physical abilities between the students of the ordinary class and the sports class appeared in nine cases. In eight cases, the mean result in physical abilities was better in the sports classes than in the ordinary classes. Based on the results of our study, we can recommend parents to enrol their children in sports classes, as presumably their physical abilities improve.

In their stature and physical abilities, the students of primary school classes of Tallinn Lilleküla Secondary School are similar to their peers Estonia.

\section{REFERENCES}

1. Crocker, P.R.E., Eklund, R.C., Kowalski, K.C. (2000). Children's physical activity and physical self-perceptions. Journal of Sport Sciences, 18, 383-394.

2. Fox, K.R. (2000). Self-esteem, self-perceptions and exercise. International Journal of Sport Psychology, 31, 228-240.

3. Harro, M., Oja L. (2001). Kehalise võimekuse testimine eelkooli- ja nooremas koolieas.

4. Koskel S., Tiit, E.-M., Kaarma, H. (2010). Changes in Estonian school students' height and weight in ten last years. Papers on Anthropology, XIX, 211-229.

5. Knussmann R. (1988). Anthropologie. Handbuch der vergleichenden Biologie des Menschen. Band I: Wesen und Methoden der Anthropologie. Stuttgart, New York: Gustav Fischer, 139-309.

6. Lasting, P., Miil, M., Ööbik, P. (1991). Õpilaste kehalised võimed ja nende mõõtmine. Eesti Oppekirjanduse Keskus. Tallinn. 
7. Martin, R. (1928). Lehrbuch der Anthropologie. Erster Band. Somatologie. Jena: Verlag von Gustav Fisher.

8. Ntoumanis, N., Standage, M. (2009). Motivation in physical education classes: A self-determination theory perspective. Theory and Research in Education, 7, 194-202.

9. Thogersen, C., Fox, K.R., Ntoumanis, N. (2002). Testing the mediating role of physical acceptance in the relationship between physical activity and selfesteem: An empirical study with Danish public servants. European Journal of Sport Science, 2, 1-10.

10. Weineck, J., Jalak, R. (2008). Kehalised võimed ja organism. Tartu: Medisport.

11. Welk, G.J., Eklund, B. (2003). Validation of the children and youth self-perception profile for young children. Psychology of Sport and Exercise, 6, 51-65.

\section{Address for correspondence:}

Raini Stamm

Tallinn University

School of Natural Sciences and Health

Narva street 29, 10120 Tallinn, Estonia

E-mail: raini.stamm@tlu.ee 